\title{
SURFACE MODIFICATION OF cp-Ti AND Ti-6Al-4V BY WET BLASTING TECHNIQUE FOR BIOMEDICAL APPLICATION
}

\author{
Achariya RAKNGARM ${ }^{\mathrm{a}}$, Kousei OYAMA ${ }^{\mathrm{b}}$, Yoshiharu MUTOH $^{\mathrm{c}}$ \\ ${ }^{a}$ Graduate Student, Nagaoka University of Technology, Kamitomiokamachi 1603-1, Nagaoka, \\ ${ }^{a}$ Undergraduate Student, Nagaoka University of Technology, Kamitomiokamachi 1603-1, Nagaoka, \\ 'Dept. of Mechanical Engineering, Nagaoka University of Technology
}

KEY WORDS: wet blasting, hydroxyapatite

\section{ABSTRACT}

The cp-Ti and Ti-6Al-4V substrates were blasted with $\mathrm{HAp}$ and $\mathrm{HAp} / \mathrm{Ti}$ mixed powders at room temperature using a wet blasting machine. The surface of substrate was found to be coated with HAp and HAp/Ti composite which was clearly showed HAp peaks from both $\mathrm{XRD}$ and EDS analysis. Anyhow, $\mathrm{CaTiO}_{3}$ was occurred at low volume ratio of $\mathrm{HAp}$ in HAp/Ti mixed powder. The HAp attached tightly to the substrate, at least at the microscope level. It was stable against ultrasonic vibration for at least $5 \mathrm{~min}$. The reaction between HAp and its substrate might be strong mechanochemical bonding which could produce a strong coating for biomedical application.

\section{INTRODUCTION}

Blasting technique is commonly employed to clean surfaces and to achieve both microretentive topography and increased surface area. Interestingly, the blasted particle sticks to the plate in some cases[1-2]. Generally, the blasting impact not only affects the metal surface but additionally leads to the deformation and in some cases to the total disintegration of the grain itself [3]. If hydroxyapatite (HAp) powders and/or HAp/Ti mixed powders stick to the titanium substrate, it may be possibility to create a strong bonding between the coating layer and the substrates by the deformation of the substrates surface. So, the main goal of the present work was the development of a reproducible method which create HAp and/or HAp/Ti layer on cp-Ti and Ti-6Al-4V substrate for biomedical application.

\section{EXPERIMENTAL PROCEDURES}

Commercial pure titanium (cp-Ti) and Ti-6Al-4V plates were used as substrates in this study. The $\mathrm{cp}-\mathrm{Ti}$ and Ti-6Al-4V with a size of $10 \times 50 \times 3 \mathrm{~mm}^{3}$ were cleaned ultrasonically in distilled water, acetone, and ethanol for $20 \mathrm{~min}$. After that, the substrates were ultrasonically cleaned again in distilled water for another 10 min and then dried in air. Hydroxyapatite (HAp) powders (Taihei Chemical) were sintered at $1,150^{\circ} \mathrm{C}$ for an hour. Subsequently, HAp sintered clusters were milled in a ball milling to obtain HAp sintered powders. The round Ti powder (Sumitomo Titanium Corporation) was mixed with the sintered HAp powders. This mixed powders of HAp $(25 \mu \mathrm{m}) / \mathrm{Ti}(45 \mu \mathrm{m})$ were used for wet blasting at chamber pressure of $0.20 \mathrm{MPa}$ with blasting pressure of $0.25 \mathrm{MPa}$. The mixed powders of $100 \mathrm{ml}$ were feed into $400 \mathrm{ml}$ distilled water in the chamber of blasting machine. The stirrer was operated during the blasting processes.

\section{RESULTS AND DISCUSSION}

Table 1 shows the volume ratio of HAp/Ti mixed powders which were blasted on both $\mathrm{cp}-\mathrm{Ti}$ and $\mathrm{Ti}-6 \mathrm{Al}-4 \mathrm{~V}$ substrates. It can be seen that all of the blasting conditions were successfully blasted to the substrates. The EDS analysis of the cp-Ti and Ti-6Al-4V substrates before and after blasting processes are also shown in Table 1 . The $\mathrm{Ca} / \mathrm{P}$ molar values of the specimens after blasting were almost the same, which is close to those of human bone (1.67).

Table 1 The various blasting condition on $\mathrm{cp}-\mathrm{Ti}$ and Ti-6Al-4V with its existing phase(s) after blasting process

\begin{tabular}{|c|c|c|c|c|}
\hline \multirow{2}{*}{$\begin{array}{c}\text { HAp/Ti } \\
\text { vol. percent }\end{array}$} & \multicolumn{2}{|c|}{ Ca/P ratio } & \multicolumn{2}{c|}{ Phase(s) existed } \\
\cline { 2 - 5 } & $\mathrm{cp}-\mathrm{Ti}$ & $\mathrm{Ti}-6 \mathrm{Al}-4 \mathrm{~V}$ & $\mathrm{cp}-\mathrm{Ti}$ & Ti-6Al-4V \\
\hline $20 \% \mathrm{HAp}: 80 \% \mathrm{Ti}$ & 1.77 & 1.71 & Calcium Titanate, HAp & HAp \\
\hline $40 \% \mathrm{HAp}: 60 \% \mathrm{Ti}$ & 1.73 & 1.69 & $\mathrm{HAp}$ & $\mathrm{HAp}$ \\
\hline $80 \% \mathrm{HAp}: 20 \% \mathrm{Ti}$ & 1.70 & 1.76 & $\mathrm{HAp}$ & $\mathrm{HAp}$ \\
\hline pure HAp & 1.76 & 1.81 & HAp & HAp \\
\hline
\end{tabular}

For further identification of the surface, XRD analysis was carried out. The XRD results are also shown in Table 1 . Phases corresponding to the titanium and HAp powder were found on $\mathrm{cp}-\mathrm{Ti}$ and Ti-6Al-4V substrates after blasting show. At 20\% HAp volume ratio, $\mathrm{CaTiO}_{3}$ was co-existed and clearly observed through XRD. Thus, there was some compositional or crystallographic change during blasting process, especially, at higher volume percent of titanium powder contents.
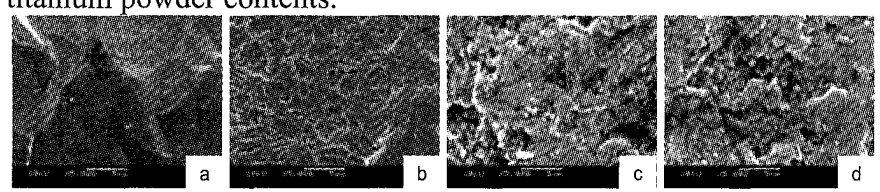

Fig 1 SEM micrographs of (a) cp-Ti, (b) Ti-6Al-4V before blasting and after blasting with pure HAp for (c) cp-Ti, (b) Ti-6Al-4V substrates.

It is commonly known that titanium surface is covered with $\mathrm{TiO}_{2}$. This oxide layer is thin and extremely fast to form within a few second. If the tiny particle of $\mathrm{HAp}$ hit with $\mathrm{Ti} / \mathrm{TiO} 2$ particle, the released energy would cause the decomposition of HAp and Caion would be released. On the other hand, $\mathrm{TiO}_{2}$ is an amphoteric oxide, it could easily react with any substance in both acidic and/or basic region. When Ca-ion impacted with $\mathrm{TiO}_{2}$ with enough activation energy, $\mathrm{CaTiO}_{3}$ may occur. However, at volume ratios of HAp higher than $40 \%$, there were no compositional or crystallographic changes during blasting process.

Figure 1 shows the SEM micrographs of the substrate surface before and after blasting. It is found that the HAp attached tightly to the substrate, at least at the SEM level. In additions, it was stable against ultrasonic vibration for at least $5 \mathrm{~min}$. So, the reaction between HAp and substrate may cause strong mechanochemical bonding.

\section{CONCLUSION}

Wet blasting of HAp/Ti mixed powderson $\mathrm{cp}-\mathrm{Ti}$ and Ti$6 \mathrm{Al}-4 \mathrm{~V}$ substrates were success. There was no compositional or crystallographic change during blasting process at volume ratios of HAp higher than $40 \%$. The minor phase of $\mathrm{CaTiO}_{3}$ was observed only at $20 \%$ volume ratio of HAp. Anyhow, the HAp powders were remained on the substrate even after ultrasonic cleaning. The reaction between HAp and substrate may cause strong mechanochemical bonding.

\section{REFERENCES}

[1] Ishikawa, K., Miyamoto, Y., Nagayama, M., Asaoka, K., Blast coating method: new method of coating titanium surface with hydroxyapatite at room temperature, J. Biomed. Mat. Res. 1997;88(2):129-134.

[2] Kern, M., Thompson, V. P., Effects of sandblasting and silica coating procedures on pure titanium, J. Dent. 1994;22:300-306.

[3] Gbubeck, U., Masten, A., Probst, J., Thull, R., Tribochemical structuring and coating of implant metal surfaces with titanium oxide and hydroxyapatite layers, J. Mat. Sci. \& Eng. C. 2003;23:461-465 